\title{
Consumer Durable Spending: Explanation and Prediction
}

IN AN EARLIER PAPER presented to the Brookings Panel on Economic Activity, I attempted to survey the extent to which recent consumer behavior would have been "understood" by some of the principal U.S. forecasting models in the absence of concurrent errors emanating from other sectors of the economy. ${ }^{1}$ At that time, I concluded that the errors in forecasting that reflected most seriously on the structure and composition of the typical forecasting equations concerned consumer durable expenditures, particularly for automobiles. An attempt to improve the explanatory power and forecasting ability of a stock-adjustment automobile equation by incorporating a household wealth variable was notably unsuccessful.

The analysis reported in the present paper stems from the findings in the earlier report. The concentration here is on consumer durables, especially automobiles. While the wealth variable has been abandoned for the present, its prime mover-the stock market-continues to play a significant role in the investigation, both directly, and indirectly as a possible source of changes in consumer sentiment.

In the majority of econometric consumption equations in standard use as forecasting tools, variables directly reflecting consumer sentiment play

* I wish to acknowledge, besides help from participants in the Brookings Panel, valuable comments from Robert Holbrook, Eva Mueller, and Lester Taylor, and the research assistance of Richard Hokenson.

1. Saul H. Hymans, "Consumption: New Data and Old Puzzles," Brookings Papers on Economic Activity (1:1970), pp. 117-26. 
little if any part. ${ }^{2}$ If changes in consumer sentiment affect expenditures, and if the pattern of changing sentiment is adequately accounted for by the other, commonly used variables, then the absence of a direct sentiment variable is of little consequence. If the second proviso is false, however, then the forecasting equations in common use are-at best-adequate only when consumer sentiment is in some sense average or normal. ${ }^{3}$ Since it is nearly axiomatic that the past few years have been abnormal from an economic point of view, this seems a particularly appropriate time to question the adequacy of the standard sentiment-free equations.

The next section of the paper deals with an attempt to explain the systematic changes in consumer sentiment in order to permit the use of a consumer sentiment index in the forecasting of durable expenditures. The following two sections deal with expenditures on automobiles and on other durables, setting out explanatory equations and testing them on postsample data for 1969 and 1970. The paper concludes with projections of consumer durable expenditures through 1972 corresponding to likely alternative paths of economic growth, inflation, and the stock market.

\section{The Index of Consumer Sentiment}

For more than two decades the Survey Research Center of the University of Michigan has been gathering data intended to measure the mood

2. The common lack of sentiment variables is typified in equations to be found in Gregory C. Chow, "Statistical Demand Functions for Automobiles and Their Use for Forecasting," in Arnold C. Harberger (ed.), The Demand for Durable Goods (University of Chicago Press, 1960); H. S. Houthakker and Lester D. Taylor, Consumer Demand in the United States, 1929-1970: Analyses and Projections (Harvard University Press, 1966); and Arnold Zellner, "The Short-Run Consumption Function," Econometrica, Vol. 25 (October 1957), pp. 552-67. There are exceptions, of course, notably some of the work of Suits; see, for example, Daniel B. Suits and Gordon R. Sparks, "Consumption Regressions with Quarterly Data," in James S. Duesenberry and others (eds.), The Brookings Quarterly Econometric Model of the United States (Rand McNally, 1965). In addition, the Wharton model contains an "alternate" automobile equation which incorporates a consumer sentiment variable; see Michael K. Evans and Lawrence R. Klein, Programmed by George R. Schink, The Wharton Econometric Forecasting Model (2nd ed., University of Pennsylvania, Economics Research Unit, 1968). Finally, Ray C. Fair of Princeton University has recently done some work involving the use of sentiment variables as integral parts of a macroeconometric forecasting model.

3. For a similar and more detailed discussion of this point, see F. Thomas Juster and Paul Wachtel, "A Note on Uncertainty, Expectations, and Durable Goods Demand Models" (processed; National Bureau of Economic Research, August 1970). 
of consumers with regard to near-term purchases of major durable goods. ${ }^{4}$ In the period since the Korean war, the center has constructed an index of consumer sentiment (ICS) based on national survey answers to five key questions. ${ }^{5}$ In the early sixties Mueller and Friend and Adams reviewed the accumulated ten-year record of the ICS as a forecaster of consumer durable expenditures, particularly automobiles. ${ }^{6}$

While it is well known that the consumer's mood is affected by (and affects) general business conditions, it is equally well known that income alone is a poor predictor of the ICS. ${ }^{7}$ It is partly on this basis that the proponents of the ICS have argued for its independent value as a determinant of consumer spending. That there is much more to the ICS than just income is not surprising. Katona, for example, has always stressed the importance of unique events, obviously not susceptible to ex ante forecasting, in the determination of consumer sentiment. A careful reading of his work, however, reveals a number of candidates as systematic and measurable determinants of changes in consumer mood. ${ }^{8}$

Those measurable elements, which recur repeatedly in Katona's discussions, involve income, stock prices, and the rate of inflation. In attempting to explain quarterly changes in consumer sentiment, I have therefore employed the following variables:

1. The ratio of real disposable income (net of transfer payments) lagged one quarter to a lagged eight-quarter average of real disposable income. If the eight-quarter average represents the level of income to which consum-

4. George Katona and others, Survey of Consumer Finances (University of Michigan, Institute for Social Research, Survey Research Center, various years).

5. The questions relate to how people "feel they are getting along" financially and "feel about business conditions" over the coming year; whether they "feel this is a good time" to buy major durables, and so forth. They have been discussed at length in William C. Dunkelberg, "Forecasting Consumer Expenditures with Measures of Attitudes and Expectations" (doctoral thesis, University of Michigan, 1969); George Katona and Eva Mueller, Consumer Attitudes and Demand, 1950-1952 (University of Michigan, Institute for Social Research, Survey Research Center, 1953); and Eva Mueller, "Ten Years of Consumer Attitude Surveys: Their Forecasting Record," Journal of the American Statistical Association, Vol. 58 (December 1963), pp. 899-917.

6. Mueller, "Ten Years of Consumer Attitude Surveys"; and Irwin Friend and F. Gerard Adams, "The Predictive Ability of Consumer Attitudes, Stock Prices, and Non-Attitudinal Variables," Journal of the American Statistical Association, Vol. 59 (December 1964), pp. 987-1005.

7. Mueller, "Ten Years of Consumer Attitude Surveys," Table 1.

8. See, for example, George Katona, "Short-Term Outlook in the United States," in The Economic Outlook for 1970, Paper presented to the Seventeenth Annual Conference on the Economic Outlook, University of Michigan, 1969 (1970). 
ers are well adjusted, then the ratio measures any deviation from that average and thus the immediate tone of business conditions that may be thought to have a significant impact on consumer sentiment.

2. The rate of increase of common stock prices in the preceding quarter.

3. The rate of increase of a lagged four-quarter average of common stock prices. This is intended to measure the underlying market trend, whereas variable (2) measures more transitory movements in the stock market.

4. The ratio of consumer prices to an eight-quarter average of consumer prices. The reasoning here is analogous to that given for the income ratio. Persistent inflation, of course, would be expected to dampen consumer sentiment. ${ }^{9}$

Table 1 presents the results of using these variables to explain changes in consumer sentiment. Each of them clearly plays a significant role in the empirical determination of the sentiment index; taken together with the lagged index, they explain nearly 80 percent of the variation in ICS. Equation (4) has two additional characteristics to recommend it. Once all four variables have been included, the importance of the lagged dependent variable is substantially diminished, and the constant term becomes insignificant-as it should be since there is no discernible trend in the ICS series. ${ }^{10}$

The usefulness of equation (4) as a predictor of the ICS is established as follows: A series of simple equations involving only income, changes in income or averages of income, and a strike-period variable were fitted to explain consumer expenditures on automobiles. In each case the lagged ICS was a significant additional variable, as discovered earlier by Mueller

9. It is possible that inflation might dampen consumer sentiment but hasten consumer spending. In a test for this possibility in the context of the automobile expenditures model described in the next section, no empirical support could be found.

10. The ICS is available sporadically before $1961: 4$, and as a continuous quarterly series after that date. Equations (1)-(4) were fitted over the observations 1962:1-1968:4 and 1956:3, 1956:4, 1958:1, 1958:2, 1960:1, 1960:2, 1961:1, and 1961:2, the last eight being quarters for which ICS and its lagged value are both available. The data were also split into two sets: (a) the early eight quarters and (b) the continuous series of twentyeight quarters, and equation (4) was fitted to each set. The procedure developed by Gregory C. Chow in "Tests of Equality Between Sets of Coefficients in Two Linear Regressions," Econometrica, Vol. 28 (July 1960), pp. 591-605, was applied to test for a structural difference between the two periods. The observed $F$-statistic (with 6 and 24 degrees of freedom) was 0.71 , indicating no evidence to support separating the data points. 
Table 1. Coefficients of the Variables in Equations To Explain the Index of Consumer Sentiment, Selected Quarters 1956-68 ${ }^{\mathrm{a}}$

\begin{tabular}{|c|c|c|c|c|c|c|c|c|}
\hline $\begin{array}{l}\text { Equa- } \\
\text { tion }\end{array}$ & $\frac{D Y K T R_{-1}}{A V D Y K T R_{-1}}$ & $\frac{S P_{-1}}{S P_{-2}}$ & $\frac{A V S P_{-1}}{A V S P_{-2}}$ & $\frac{P C E D}{A V P C E D}$ & $I C S_{-1}$ & Constant & $\bar{R}^{2}$ & $\begin{array}{l}\text { Durbin- } \\
\text { Watson } \\
\text { statistic }\end{array}$ \\
\hline (1) & $\begin{array}{r}29.344 \\
(0.61)\end{array}$ & $\ldots$ & $\ldots$ & $\ldots$ & $\begin{array}{l}0.805 \\
(4.88)\end{array}$ & $\begin{array}{r}-11.876 \\
(0.31)\end{array}$ & 0.710 & 2.30 \\
\hline (2) & $\begin{array}{r}68.442 \\
(1.50)\end{array}$ & $\begin{array}{r}26.011 \\
(2.95)\end{array}$ & $\ldots$ & ... & $\begin{array}{l}0.638 \\
(4.01)\end{array}$ & $\begin{array}{r}-62.919 \\
(-1.62)\end{array}$ & 0.765 & 2.31 \\
\hline (3) & $\begin{array}{r}74.594 \\
(1.67)\end{array}$ & $\begin{array}{r}21.199 \\
(2.31)\end{array}$ & $\begin{array}{c}30.169 \\
(1.55)\end{array}$ & ... & $\begin{array}{l}0.550 \\
(3.33)\end{array}$ & $\begin{array}{r}-86.621 \\
(-2.12)\end{array}$ & 0.775 & 2.16 \\
\hline (4) & $\begin{array}{r}73.264 \\
(1.72)\end{array}$ & $\begin{array}{c}19.171 \\
(2.18)\end{array}$ & $\begin{array}{c}34.759 \\
(1.86)\end{array}$ & $\begin{array}{r}-122.927 \\
(-2.07)\end{array}$ & $\begin{array}{l}0.479 \\
(2.98)\end{array}$ & $\begin{array}{r}43.781 \\
(0.59)\end{array}$ & 0.796 & 2.10 \\
\hline
\end{tabular}

Note: The dependent variable is the Survey Research Center Index of Consumer Sentiment (ICS), first quarter $1966=100$.

Definition of symbols:

$D Y K T R=$ disposable personal income net of transfer payments, billions of 1958 dollars,

$A V D Y K T R=\frac{1}{8} \sum_{0}^{7} D Y K T R_{-i}$,

$S P=$ Standard and Poor index of 425 industrial common stocks, 1941-43 $=10$,

$A V S P=\frac{1}{4} \sum_{0}^{3} S P_{-i}$,

$P C E D=$ implicit price deflator for personal consumption expenditures, $1958=100$,

$A V P C E D=\frac{1}{8} \sum_{0}^{7} P C E D_{-i}$,

ICS $=$ index of consumer sentiment.

Here and in subsequent empirical equations, $t$ statistics are shown in parentheses beneath the coefficients, and $\bar{R}^{2}$ is adjusted for degrees of freedom.

a. See note 10 , p. 176, for the quarters covered.

among others. ${ }^{11}$ To test the usefulness of the equation predicting ICS, two separate series were employed as an alternative to ICS: the predicted values and the residuals from equation (4), the former series denoted by ICSHAT and the latter by NOISE. In each of the income-type equations, the actual ICS series was then replaced by ICSHAT and NOISE. Since by definition $I C S=I C S H A T+N O I S E$, the resulting equation could insist that the power of the ICS variable derives mainly from its predictable component, or from its unpredictable, "psychological" component, or from some combination of the two. A typical result of these experiments is shown in Table 2. Note first that the use of ICSHAT and NOISE in place of ICS has essentially no impact on the income coefficient or any summary statistic. The coefficient of ICSHAT in equation (6) is practically the same

11. Mueller, "Ten Years of Consumer Attitude Surveys." 
Table 2. Coefficients of the Variables in Equations To Predict Automobile Expenditures, Selected Quarters 1956-68

\begin{tabular}{|c|c|c|c|c|c|c|c|c|}
\hline $\begin{array}{l}\text { Equa- } \\
\text { tion }\end{array}$ & $D Y K T R_{-1}$ & STRIKE & $I C S_{-1}$ & $I C S H A T_{-1}$ & $N O I S E_{-1}$ & Constant & $\begin{array}{c}\text { Stan- } \\
\text { dard } \\
\text { error } \\
\text { of } \\
\text { esti- } \\
\text { mate }\end{array}$ & $\begin{array}{l}\text { Durbin- } \\
\text { Watson } \\
\text { statistic }\end{array}$ \\
\hline (5) & $\begin{array}{c}0.111 \\
(22.57)\end{array}$ & $\begin{array}{l}1.745 \\
(3.62)\end{array}$ & $\begin{array}{c}0.126 \\
(2.66)\end{array}$ & $\ldots$ & $\ldots$ & $\begin{array}{r}-26.996 \\
(-5.71)\end{array}$ & 1.32 & 1.11 \\
\hline (6) & $\begin{array}{c}0.111 \\
(22.12)\end{array}$ & $\begin{array}{l}1.753 \\
(3.57)\end{array}$ & $\ldots$ & $\begin{array}{c}0.121 \\
(2.28)\end{array}$ & $\begin{array}{l}0.147 \\
(1.40)\end{array}$ & $\begin{array}{r}-26.546 \\
(-5.10)\end{array}$ & 1.34 & 1.11 \\
\hline
\end{tabular}

Note: The dependent variable is the seasonally adjusted annual rate of consumer expenditures on automobiles and parts in the national income accounts, in billions of 1958 dollars.

Definition of symbols:

$D Y K T R=$ disposable personal income net of transfer payments, billions of 1958 dollars,

STRIKE = values to account for auto strikes against General Motors in 1964 and against Ford in 1967: -2 in $1964: 4 ;+1$ in $1965: 1$ and $1965: 2 ;-1$ in $1967: 4$; and $+1 / 2$ in $1968: 1$ and 1968:2,

ICS $=$ index of consumer sentiment

$I C S H A T=$ predicted values of ICS from equation (4),

NOISE $=$ residuals from equation (4).

a. See note 10 , p. 176 , for quarters covered.

as that of ICS in (5) and the $t$ values are also quite close. The nonsystematic component, NOISE, is surely not useless in equation (6), though its $t$ value is by far the lowest of any variable in the equation.

From these experiments, it may be concluded that the predictions of ICS obtained by use of equation (4) are apt to prove helpful in forecasting consumer spending if, indeed, it can be shown that ICS itself is important. Economic forecasting has progressed a good deal beyond the naïve incometype equations typified in Table 2. That ICS is an important addition to equations using income alone is no longer a sufficient recommendation.

\section{The Determination of Auto Expenditures}

It is generally agreed that expenditures on durable goods are best explained in a so-called stock-adjustment framework. In such a setting, the "desired," or equilibrium, stock of a durable commodity is taken to depend on certain economic variables, such as income and prices. Gross expenditure on the commodity is then taken to depend on the difference between the desired stock and the stock already available as a result of prior purchases, and on the need to replace old stock as it wears out. For 
the case of automobile expenditures, the model may be formulated as follows. The desired stock $K A^{*}$ is given by

$$
K A^{*}=a+b\left(D Y K T R_{-1}\right)+c\left(U M_{-1}\right)+d\left(\frac{A U T O D}{P C E D}\right),
$$

where

$D Y K T R=$ disposable personal income, net of transfers, in billions of 1958 dollars,

$U M=$ the unemployment rate for males 20 years of age and over, in percent,

$A U T O D=$ implicit auto price deflator, $1958=100$,

$P C E D=$ implicit price deflator for personal consumption expenditures, $1958=100$.

Income is measured net of transfer payments, which add little to the demand for autos. Rising unemployment is assumed to dampen the effective desire for automobiles, and the unemployment rate for males 20 years and over is chosen as one of the best indicators of overall conditions of employment. An increase in the price of automobiles relative to consumer prices in general is assumed, other things equal, to reduce the desired stock of automobiles.

Given the desired stock of automobiles, gross real expenditures on autos are taken to be described by the following equation:

$$
C A R K=w\left(K A^{*}-K A_{-1}\right)+v K A_{-1},
$$

where

$C A R K=$ consumer expenditures on autos and parts in the national income accounts, adjusted to remove mobile homes, ${ }^{12}$ in billions of 1958 dollars, seasonally adjusted at annual rates,

$K A=$ the actual auto stock, end of quarter, multiplied by four to accord with the annual rate of income, ${ }^{13}$

$w=$ the quarterly rate of adjustment between desired and actual stock,

$v=$ the quarterly rate of depreciation, calculated on the decliningbalance method.

12. The Office of Business Economics of the Department of Commerce provided data that made it possible to remove mobile home expenditures from the published data on auto expenditures. In 1969 , the adjustment was about $\$ 21 / 2$ billion (current dollars)

13. The construction of the auto stock series is discussed in the appendix. 
Substituting the expression for $K A^{*}$ in equation (7) into equation (8) and rearranging terms yields equation (9), which is to be estimated statistically.

$$
\begin{aligned}
C A R K= & a w+b w\left(D Y K T R_{-1}\right)+c w\left(U M_{-1}\right) \\
& +d w\left(\frac{A U T O D}{P C E D}\right)-(w-v) K A_{-1} \cdot{ }^{14}
\end{aligned}
$$

In equation (10), which is based on a stock-adjustment view and corrects for serial correlation, the Durbin-Watson is comfortably near 2 and the measured value of the serial correlation coefficient, denoted $r$, is nearly $2 / 3 .{ }^{15}$

$$
\begin{aligned}
C A R K= & 19.009+0.206 \text { DYKTR } \\
& (2.93)(9.14) \quad 0.753 U M_{-1} \\
- & 25.861 \frac{A U T O D}{P C E D}-0.157 K A_{-1}+\underset{(-6.33)}{1.626} \text { STRIKE. } \\
& (-4.40)
\end{aligned}
$$

$\bar{R}^{2}=0.961$, standard error of estimate $=1.128$, Durbin-Watson $=1.82, r=0.643$.

Here and in subsequent empirical equations, $t$ statistics are shown in parentheses beneath the coefficients, and $\bar{R}^{2}$ is adjusted for degrees of freedom.

14. The following is the result of estimating equation (9) by least squares using quarterly data for 1954-68:

$$
\begin{aligned}
& C A R K=14.465+0.165 D^{0} Y K T R_{-1}-0.885 U M_{-1}-18.549 \frac{\text { AUTOD }}{\text { (1.90) }(6.06)} \\
& -0.108 K A_{-1}+1.787 \text { STRIKE. } \\
& \text { (-3.63) (3.40) } \\
& \bar{R}^{2}=0.937 \text {, standard error of estimate }=1.438 \text {, Durbin-Watson }=0.80 \text {. }
\end{aligned}
$$

While the equation fits very well and all coefficients are significant and of reasonable magnitude, the Durbin-Watson statistic of 0.80 clearly signals the presence of strong serial correlation in the residuals and thus questions the reliability of the fitted coefficients.

A Durbin-Watson of approximately 2 indicates a random pattern in the equation errors. A statistic well below 2 indicates long runs of overprediction by the equation followed by long runs of underprediction. A statistic well above 2 indicates a pattern of over- and underprediction alternating too frequently to be considered random. Either deviation from a DW of about 2 is indicative of systematic errors that question the validity of the fitted equation. It is mathematically impossible for a calculated DW to lie outside the range of 0 to 4 , and thus the 0.80 of the least squares equation is suspiciously low.

15. Because the lagged stock contains the lagged value of the dependent variable, the serial correlation coefficient was calculated using residuals generated from equation (9) fitted by using instrumental variables for $K A_{-1}$. This provides for consistent estimation; see Marc Nerlove, Estimation and Identification of Cobb-Douglas Production Functions (Rand McNally, 1965), pp. 157-90. 
The coefficient of the lagged stock measures the difference between the quarterly rates of adjustment $w$ and depreciation $v$. With the latter estimated to be 0.078 per quarter (see the appendix), equation (10) implies a value of $w$ equal to $0.235(0.157+0.078)$, or 23.5 percent, for the adjustment of the discrepancy between actual and desired auto stock.

The income and price coefficients in equation (10) are probably most interesting viewed as elasticities. Table 3 contains both the short-run (one-

Table 3. Income and Price Elasticities for Auto Expenditures, Equations (10)-(13)

\begin{tabular}{lrr}
\hline $\begin{array}{c}\text { Equation and type } \\
\text { of elasticity }\end{array}$ & $\begin{array}{l}\text { Short-run } \\
\text { elasticity }\end{array}$ & $\begin{array}{c}\text { Long-run } \\
\text { elasticity }\end{array}$ \\
\hline (10) & 3.08 & 1.02 \\
Income & -1.07 & -0.36 \\
Price & & \\
$(11)$ & 2.91 & 1.01 \\
Income & -1.17 & -0.41 \\
Price & & \\
(12) & 2.55 & 1.02 \\
Income & -1.14 & -0.46 \\
Price & & \\
(13) & 2.72 & 1.06 \\
Income & -0.78 & -0.30 \\
Price & & \\
\hline
\end{tabular}

quarter) and long-run income and price elasticities, evaluated at the means, corresponding to equation (10) ${ }^{16}$ In the short run an increase in income leads to a far more than proportionate increase in auto expenditures. This effect wears off once the auto stock begins to rise, however, and in the long run income and auto spending rise proportionately. On the other hand, while price and quantity changes move nearly proportionately in the short run, a price increase leads in the long run to a less than proportionate reduction in quantity purchased. The automobile has apparently become so necessary in the American economy that its price

16. The short-run elasticities correspond to the first-quarter impact on expenditures. The long-run elasticities measure the final expenditure effects after all adjustment has taken place, or-what amounts to the same thing-after the effect on the desired stock of automobiles has been completely carried through into the actual stock. The method of calculating the long-run elasticities is explained in the appendix. 
elasticity is beginning to resemble that of food. In earlier studies based on combinations of pre- and post-World War II data, Chow and Suits obtained long-run price elasticities of -0.7 and -0.6 respectively. ${ }^{17}$ The further decline obtained in this study based on the most recent data is not unexpected. ${ }^{18}$

A number of experiments were performed in an effort to work the consumer sentiment index directly into the stock-adjustment analysis of auto expenditures. It was thought that consumer sentiment might affect the adjustment rate in the model, that is, the adjustment would be more rapid the "better" the mood of consumers. Such a conjecture was in no way empirically supported. Attempts to permit the level of the sentiment index (with or without lags) to affect the desired stock, either directly or in conjunction with income, proved fruitless. A qualified success was obtained when the lagged change in the sentiment index was introduced as a determinant of the desired stock. The empirical result (after correction for serial correlation) is shown in equation (11):

$$
\begin{aligned}
C A R K= & 22.841+\underset{(8.01)}{0.195 D Y K T R_{-1}-0.758}\left(-3 M_{-1}-0.147 K A_{-1}\right. \\
& (3.08)(-5.45) \\
& -28.366 \frac{\text { AUTOD }}{\text { PCED }}+\underset{(1.35)}{0.065 \Delta(E I C S)_{-1}}+\underset{(3.87)}{1.674 S T R I K E .}
\end{aligned}
$$

$\bar{R}^{2}=0.958$, standard error of estimate $=1.175$, Durbin-Watson $=1.82, r=0.569$.

In the equation, EICS refers to ICS with the eleven missing observations between 1954:3 and 1961:3 filled in by the predicted values from equation (4).${ }^{19}$ The sentiment index is clearly the "weak sister" in the equation, and plays very little part in determination of the desired stock. This is in marked contrast to its power in an equation of the kind typified by (5) and (6). Comparing the elasticities for equations (10) and (11) in Table 3, one sees

17. Chow, "Statistical Demand Functions for Automobiles"; and Daniel B. Suits, "The Demand for New Automobiles in the United States, 1929-56," Review of Economics and Statistics, Vol. 40 (August 1958), pp. 273-93.

18. Evans, however, obtained a price elasticity of -1.5 based on data for 1948-64; see Michael K. Evans, Macroeconomic Activity: Theory, Forecasting, and Control; An Econometric Approach (Harper \& Row, 1969), Chap. 6. I am at a loss to reconcile this difference.

19. The ordinary least squares estimates of the $C A R K$ equation are not much changed whether one uses EICS or linear interpolation for the missing data points or a reduced sample that omits the missing observations. The last technique, however, requires the loss of twenty-two sample points, since equation (11) contains $\triangle E I C S$; it also makes correction for serial correlation very difficult. 
that inclusion of the sentiment index has but trivial impact on the calculated income and price elasticities.

The experiments that concluded with equation (11) all represent attempts to utilize ICS as a continuous variable. Since the purpose of introducing ICS is to test whether changes in the consumer mood affect expenditures, it is wise-particularly in view of equation (11) - to question whether continuous quarter-by-quarter differences in the measured sentiment index indeed represent meaningful changes in the buying mood of consumers. ${ }^{20}$ It is certainly possible that many of the observed quarterly changes are little more than the random movements in an essentially trendless series. During many subintervals of the sample period, little appears in the way of sustained movements in $I C S$; rather it rises and falls from quarter to quarter with no clear indication that the consumer's mood is either progressively deteriorating or progressively improving. At such times the sentiment index probably provides little, if any, useful information about consumer spending. Presumably, an attempt to measure the expenditure effects of changes in consumer mood should be accompanied by some method of filtering out such cases of possibly random movement.

Juster and Wachtel have devised a "filtered" version of the changes in the ICS. ${ }^{21}$ In a process essentially the same as theirs, the filtered variable $J$ takes on the value $0.5 \Delta E I C S_{-1}+0.5 \Delta E I C S_{-2}$ if (a) $\Delta E I C S_{-i}$ for $i=1,2,3$ are all of the same sign; or if (b) $\triangle E I C S_{-i}$ for $i=1,2$ are of the same sign and $\left|\Delta E I C S_{-1}\right|+\left|\Delta E I C S_{-2}\right| \geq 7$; if neither (a) nor (b) is fulfilled, $J$ takes on the value of 0 . Condition (a) corresponds to a directional movement that is sustained over at least three successive quarters. Condition (b) admits directional movements sustained for only two quarters, provided that the two-quarter change is sufficiently large. A change of at least 7 points over two quarters represents an average quarterly change of slightly more than the sample standard deviation of the quarterly changes in ICS, and may therefore be properly considered a "large" change in consumer sentiment. The process of averaging the previous two quarterly changes when either of the conditions occurs is essentially a smoothing process. It seems justifiable in view of the fact that many of the sustained changes in ICS proceed in a somewhat "jerkier" pattern than is likely to find its way into consumer

20. My analysis of this point benefited substantially from a conversation with $\mathrm{F}$. Thomas Juster.

21. Juster and Wachtel, "A Note on Uncertainty, Expectations, and Durable Goods Demand Models." 
spending. Over the sixty quarters in the 1954-68 sample, the filtered variable assumes a nonzero value in only seventeen.

Equation (12) indicates the results of using the variable $J$ as a determinant of the desired auto stock.

$$
\begin{aligned}
C A R K= & \underset{(3.71)}{23.071}+\underset{(7.69)}{0.171} D Y K T R_{-1}-0.767 U M_{-1}-0.117 K A_{-1} \\
(-4.02) & (-4.78) \\
& -27.867 \frac{A U T O D}{P C E D}+\underset{(-4.98)}{2} \underset{(3.85)}{0.297} \mathrm{~J}+\underset{(4.44)}{1.732} \text { STRIKE. }
\end{aligned}
$$

$\bar{R}^{2}=0.965$, standard error of estimate $=1.062$, Durbin-Watson $=1.88, r=0.523$.

The filtered sentiment change, unlike the continuous sentiment index, is clearly no "weak sister" in the equation. Its coefficient is well defined and is four and a half times the size of the coefficient of the corresponding unfiltered variable. Persistent changes in the consumer mood do indeed have a significant impact on automobile expenditures-even when explained in a stock-adjustment framework. The income and price elasticities corresponding to equation (12) are essentially the same as those for the previous equations (see Table 3).

A final result worth noting has to do with the direct influence of stock prices. The average stock-price ratio used above to explain the sentiment index was introduced into the auto equation as a term multiplied by income. The interpretation of such a construction is that persistently rising stock prices raise the desired ratio of auto stock to income. This could occur either via the mechanism of improved consumer sentiment, or, alternatively, as the reflection of a wealth effect whereby a given measured income represents higher permanent income the higher the average rate of increase of stock prices. The results are given in equation (13).

$$
\begin{aligned}
& C A R K=\underset{(1.37)}{12.097}+\left[\begin{array}{cc}
0.156+\underset{(4.91)}{0.206} & (1.69) \\
\left(A V S P P_{-2}\right.
\end{array}\right] D Y K T R_{-1}-0.122 K A_{-1} \\
& \underset{(-3.52)}{0.758} U M_{-1}-19.044 \frac{A U T O D}{P C E D}+\underset{(-2.33)}{1.680} \text { STRIKE. }
\end{aligned}
$$

$\bar{R}^{2}=0.963$, standard error of estimate $=1.106$, Durbin-Watson $=1.96, r=0.608$.

On the basis of the standard criteria, equation (13) is superior to (11), but inferior to (12). When the filtered sentiment variable is added to equation (13), it performs very well, while the stock-price variable is reduced to complete insignificance. Unless wealth and sentiment are quite highly cor- 
related, this would suggest that the stock-price variable in (13) is, for the most part, an incomplete measure of consumer sentiment.

To test equations (10)-(13), they were used to forecast auto expenditures for 1969:1-1970:2, the six known data points beyond the fit period. For this purpose, equation (14), which is the full-sample fit corresponding to equation (5), was also used.

$$
\begin{aligned}
C A R K= & -20.041+0.093 D Y K T R_{-1}+\underset{(3.61)}{0.120 \text { EICS }_{-1}} \\
& (-6.41)(30.079) \\
& +1.601 \text { STRIKE. }
\end{aligned}
$$

$\bar{R}^{2}=0.950$, standard error of estimate $=1.279$, Durbin-Watson $=2.22, r=0.74$.

The root mean square errors are shown in Table 4.

Table 4. Static and Dynamic Root Mean Square Errors Resulting from Extrapolating Equations (10)-(14) for 1969:1-1970:2a

Billions of 1958 dollars at seasonally adjusted annual rates

\begin{tabular}{ccc}
\hline Equation & $\begin{array}{c}\text { Static } \\
\text { error }\end{array}$ & $\begin{array}{c}\text { Dynamic } \\
\text { error }\end{array}$ \\
\hline$(10)$ & 1.35 & 1.92 \\
$(11)$ & 1.29 & 1.92 \\
$(12)$ & 1.18 & 1.80 \\
$(13)$ & 1.28 & 1.71 \\
$(14)$ & 2.54 & $\ldots$ \\
\hline
\end{tabular}

a. The root mean square error is the square root of the average of the squared forecasting errors.

The static errors refer to a series of one-quarter forecasts in which the actual values of all determining variables were used. In the case of equations (10)-(13), the forecasts were also calculated by forcing the equation to generate its own lagged stock from its previous forecasts of auto expenditures, in effect withholding information on the actual course of auto expenditures during the forecast period. These "dynamic" forecasts produce the dynamic root mean squared errors. All of the stock-adjustment equations clearly outperform equation (14), which typifies a more naive income approach. The stock-adjustment equation with the unfiltered sentiment index performs only marginally better than the same equation without ICS, as is consistent with the fit results. The equation with the filtered sentiment variable clearly outperforms the unfiltered version, and 
indeed achieves the minimum static error. Somewhat surprisingly, the equation with the best dynamic performance is that with the stock-price variable. This result may be somewhat misleading, however, since it stems entirely from a particularly large dynamic residual for equation (12) in the fourth quarter of 1969. None of the equations extrapolates the postsample period quite as well as each fits the sample period. But the static errors in the stock-adjustment equations are very close to the corresponding standard errors of estimate in the fitted equations, and the dynamic errors are not significantly larger. ${ }^{22}$

\section{Durables Other than Autos}

In some respects expenditures on durables excluding autos (hereafter "other durables") present a more difficult problem than expenditures for autos. The latter category consists of a well-defined, slowly changing, major product. In the case of other durables, one has to contend with a mixed bag of new and old products constantly changing in relative importance. Thus, between 1955 and 1968 the radio-television subgroup grew from 14 to 19 percent of other durables, while the furniture subgroup declined from 20 to 15 percent. Such a change in weight is complicated further by the fact that the durability of the products in the two subgroups might be quite different, thus leading to substantial changes over the sample in the aggregate depreciation rate for other durables. Another problem is illustrated by the kitchen appliance subgroup, which has held a fairly stable share of about 19 percent of other durables. No one would contend that a typical set of kitchen appliances had remained the same between 1955 and 1968.

This changing heterogeneity of other durables leads to enormous index number problems, one implication of which is the inability empirically to isolate any relative price effect in the equation for other durables expenditures. ${ }^{23}$ Another difficulty concerns the method of constructing a stock variable. This is discussed in the appendix; suffice it to say here that the

22. All of the equations-especially (14) - are biased downward over the postsample period. The mean algebraic (static) errors, in billions of 1958 dollars, are: (10), +0.55; (11), +0.54; (12), +0.54; (13), +0.47; (14), +2.40.

23. For a useful discussion of this problem, see Evans, Macroeconomic Activity, pp. 171-72. 
constructed stock series does not assume a constant depreciation rate, as was true in the case of automobiles. ${ }^{24}$ In fact, the data appear to indicate a steady decline in the quarterly depreciation rate from 12 percent in 1954 to 9.2 percent in 1967 , with evidence of a return to about 10 percent by 1969. Over the 1954-68 sample period, the mean depreciation rate is about 9.8 percent. The preferred equation for other durables is equation (15), which is corrected for serial correlation: $:^{25}$

$$
O D C K=\frac{-22.874+0.170}{(-17.10)(19.96)} \mathrm{DYK}-0.044 K O_{-1} .
$$

$\bar{R}^{2}=0.997$, standard error of estimate $=0.455$, Durbin-Watson $=1.98, r=0.84$.

Here

$O D C K=$ consumer expenditures on durables other than automobiles in the national income accounts, billions of 1958 dollars, seasonally adjusted annual rates,

$D Y K=$ disposable personal income, billions of 1958 dollars,

$K O=$ actual stock of other durables, end of quarter.

The corresponding short-term income elasticity, evaluated at the means, is 2.14 , while the long-term elasticity is calculated to be $1.48 .{ }^{26}$ Using the mean depreciation rate of 9.8 percent, the equation indicates an adjustment rate of just over 14 percent $(0.098+0.044)$ per quarter.

Despite the best of efforts, all attempts to work the consumer sentiment index-whether filtered or not-into the other durables equation met with utter failure. Apparently the sentiment index has been found to be of only marginal value even in the case of an income-type equation for other

24. This means that the depreciation rate in the other durables equation is actually a variable parameter-a matter that is here admitted, but otherwise ignored in the estimation process.

25. As in the case of auto expenditures, the Durbin-Watson statistic cautions against relying on a least squares equation for other durables.

$$
\begin{gathered}
O D C K=-20.775+0.158 D Y K-0.035 K O_{-1} . \\
(-8.57)(10.26) \quad(-2.59)
\end{gathered}
$$

$\bar{R}^{2}=0.989$, standard error of estimate $=0.831$, Durbin-Watson $=0.32$.

No attempt was made to correct for any possible simultaneity bias in the equation.

26. The long-term elasticity is evaluated not only at the mean of $O D C K$ and $D Y K$, but also at the mean value of the depreciation rate. See the appendix for details. 
durables, despite the fact that the survey questions on which the index is based apply to these durables as well as to automobiles. ${ }^{27}$

In extrapolating equation (15) over 1969:1-1970:2, the static root mean square error turns out to be 1.24 (billions of 1958 dollars), while the dynamic root mean square error is slightly smaller, 1.13 . The greater precision of the dynamic predictions is an unusual finding. Relative to the fit in the sample period, this extrapolation is markedly less satisfactory than that from the corresponding auto equations. More disaggregation might help in both specification and forecasting, and this possibility deserves exploration.

\section{Alternatives for 1970-72}

What might be called the "benchmark forecast" of economic activity over the next few years appears to indicate a resumption of growth in real gross national product for the second half of 1970 and faster but still subcapacity growth in the first half of 1971, to be followed by a further step-up after mid-1971. Such a scenario is expected to be accompanied by a reduced rate of inflation, which $I$ would peg at about 3 percent annually beginning in 1971. Table 5 contains numerical detail consistent with such a benchmark forecast, along with corresponding figures relating to unemployment and disposable income. In addition, the table contains a projection in which stock prices return by the end of 1970 to their level at the beginning of 1970 and remain there through 1972. These data are sufficient to permit a "forecast" of the consumer sentiment index, auto expenditures, and other durable expenditures through 1972. The results are given for half-years in Table 6. These should not be interpreted as real forecasts, but rather as projections conditional on the benchmark forecast specified in Table 5. In the case of auto expenditures, three projections are made, corresponding to equations (11)-(13).

The benchmark forecast permits some modest recovery in consumer

27. See Mueller, "Ten Years of Consumer Attitude Surveys." Shapiro and Angevine do seem to find a role for attitudes in a stock-adjustment equation for other durables in their study of the Canadian data; see Harold T. Shapiro and Gerald E. Angevine, "Consumer Attitudes, Buying Intentions and Expenditures: An Analysis of the Canadian Data," Canadian Journal of Economics, Vol. 2 (May 1969), pp. 230-49. 


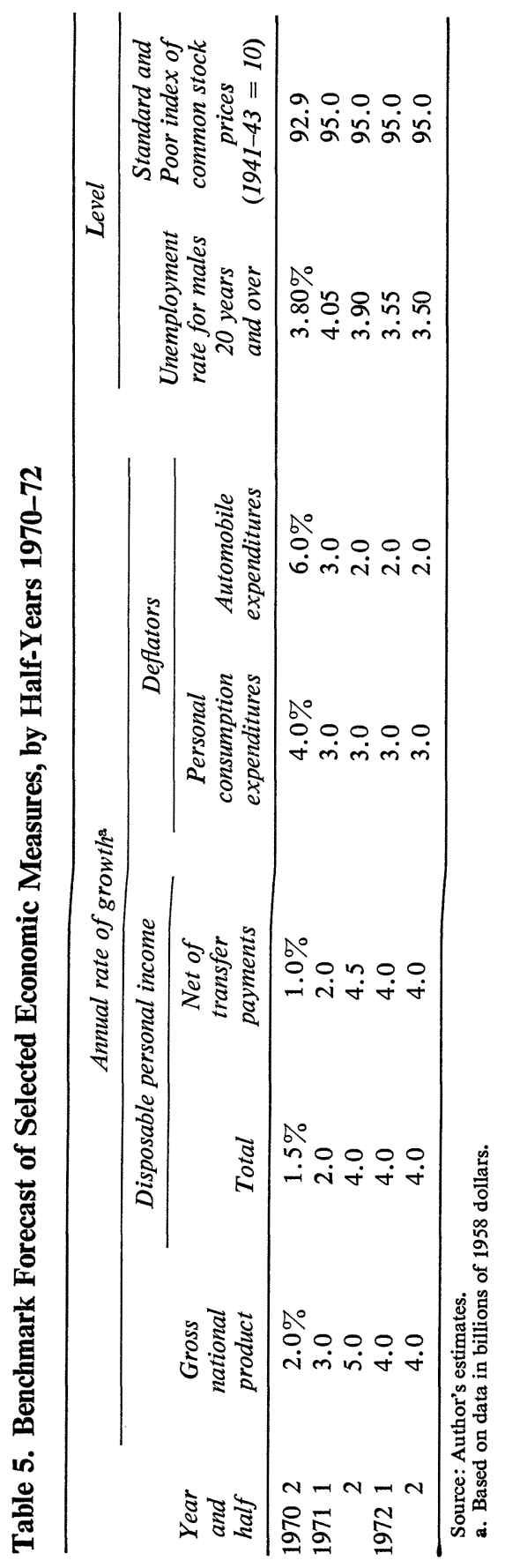




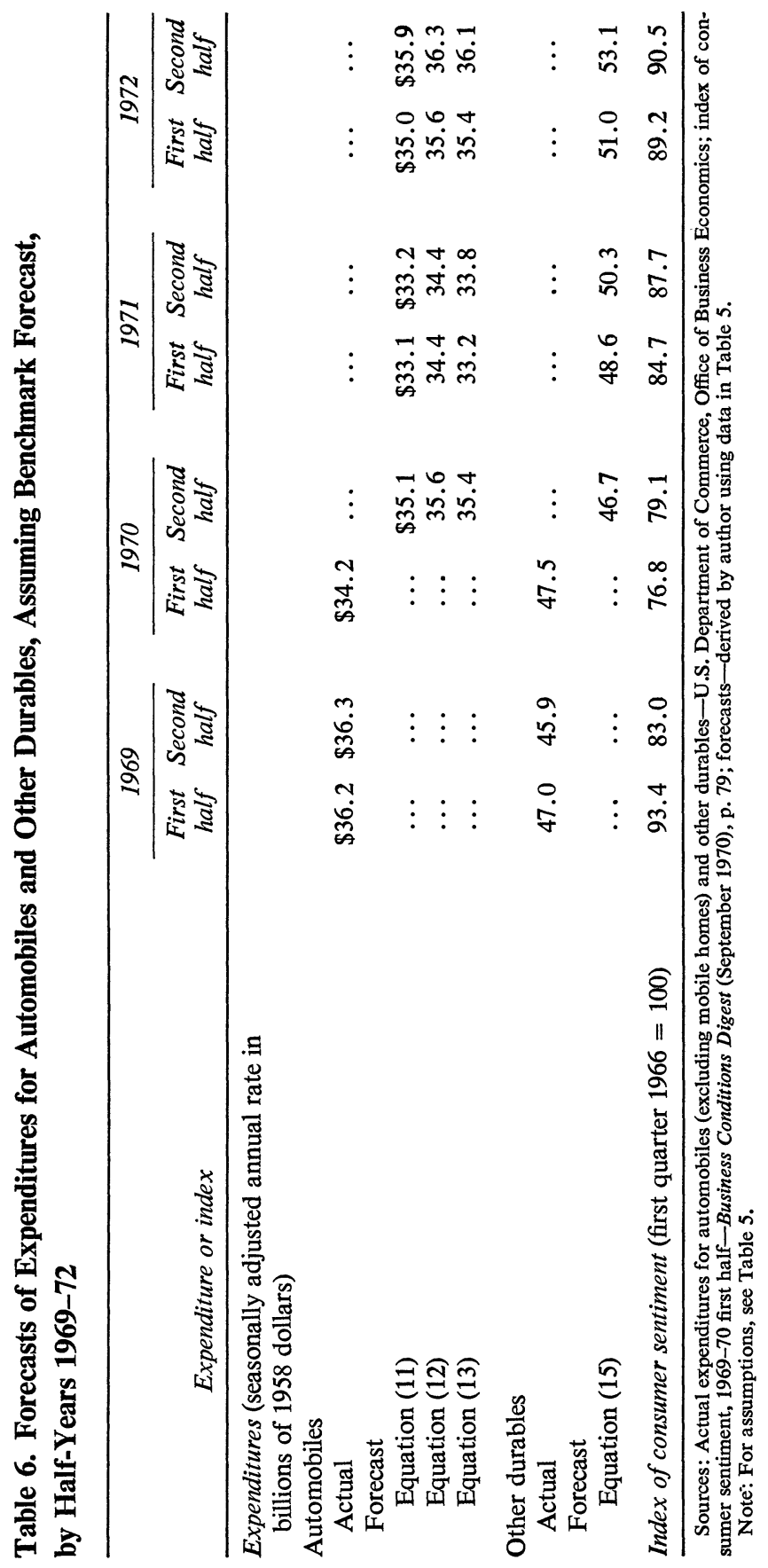


sentiment as stock prices rebound and inflation slows down, but the improvement is not strong enough to permit the sentiment index to regain its early 1969 level - even by the second half of 1972 .

Consumer expenditures on other durables hesitate briefly in the second half of 1970 but then rise by nearly 14 percent between the second half of 1970 and the second half of 1972, substantially above the increase in disposable personal income over the same period. The situation is quite different in the case of auto expenditures, which seem particularly sluggish through the end of 1971. Indeed, even by the end of 1972, auto expenditures are barely back to the level attained in 1969. The distinct bearishness that characterizes the auto market in this benchmark forecast projection is primarily the result of the pattern of income growth in the 1965-69 period. Real disposable income grew by $61 / 2$ and 51/2 percent in 1965 and 1966, respectively. These very rapid rates of growth resulted in a surge of automobile expenditures in reaction to a widening of the gap between desired and actual auto stocks. As income growth slowed to an annual average of 41/4 percent in 1967 and 1968 and declined further to only $2 \frac{1}{2}$ percent in 1969 , the continued high rate of auto purchases led to a substantial rise in the ratio of actual stock to income. Thus by the end of 1969 the stockincome ratio stood at 86 percent, compared with 76 percent four years earlier. The sluggish auto forecast displayed in Table 6 therefore follows from the existence in 1970 of a large stock overhang relative to the stockincome position that had prevailed several years earlier. In other words, the income growth projected for the next year and a half is simply not great enough to justify a further rapid growth of the auto stock from the substantial base already in existence at the start of the forecast period.

In fact, the actual expenditure levels of 1969 could not have been fully explained by the behavior of income, employment, and prices during that year. By the end of 1968, the ratio of auto stock to income had already risen to 82 percent and, as can be seen in Table 7, all of the auto equations underpredicted automobile expenditures as they attempted to react to an already large catch-up of the stock-income ratio. One might predict that 1970-71 will escape the bearish implications of a relative stock overhang, since 1969 managed to do so. This seems a weak argument. Auto spending did not rise much during 1969; it merely remained on a high plateau, and it declined in the first half of 1970. This pattern may well have markepd the very beginning of the overhang effect. An alternative explanation-namely, that a permanent structural change occurred in the late 1960s-could be 
Table 7. Difference between Actual and Predicted Auto Expenditures, by Half-Years 1969

Annual rate in billions of 1958 dollars

\begin{tabular}{lll}
\hline $\begin{array}{c}\text { Type of } \\
\text { error and } \\
\text { equation }\end{array}$ & $\begin{array}{c}\text { First } \\
\text { half }\end{array}$ & $\begin{array}{c}\text { Second } \\
\text { half }\end{array}$ \\
\hline Static & & \\
$(11)$ & 1.20 & 0.82 \\
$(12)$ & 1.03 & 1.00 \\
$(13)$ & 1.08 & 0.62 \\
Dynamic & & \\
$(11)$ & 1.68 & 2.70 \\
$(12)$ & 1.40 & 2.31 \\
$(13)$ & 1.43 & 2.35 \\
\hline
\end{tabular}

offered, but several years must pass before such a conjecture can be subjected to empirical evaluation.

Returning to the assumptions of the benchmark forecast, it may well be argued that the income-unemployment scenario in Table 5 should be accompanied by somewhat more headway against inflation and a greater recovery in stock prices. Table 8 contains projected data in which the rate

Table 8. Alternative Price and Stock Market Assumptions for Benchmark Forecast, by Half-Years 1970-72

\begin{tabular}{|c|c|c|c|}
\hline \multirow[b]{2}{*}{$\begin{array}{l}\text { Year } \\
\text { and } \\
\text { half }\end{array}$} & \multicolumn{2}{|c|}{ Annual rate of growth } & \multirow[b]{2}{*}{$\begin{array}{c}\text { Standard and } \\
\text { Poor index of } \\
\text { common stock prices } \\
(1941-43=10)\end{array}$} \\
\hline & $\begin{array}{c}\text { Personal } \\
\text { consumption } \\
\text { expenditures } \\
\text { deflator }\end{array}$ & $\begin{array}{c}\text { Automobile } \\
\text { expenditures } \\
\text { deflator }\end{array}$ & \\
\hline 19702 & $3.5 \%$ & $4.0 \%$ & 92.9 \\
\hline 19711 & 3.0 & 2.0 & 102.5 \\
\hline 2 & 2.5 & 1.5 & 112.5 \\
\hline 19721 & 2.5 & 1.5 & 115.0 \\
\hline 2 & 2.5 & 1.5 & 115.0 \\
\hline
\end{tabular}

Source: Author's estimates (see Table 5).

a. Based on data in billions of 1958 dollars.

of inflation declines more rapidly and stock prices regain their 1968 peak. The effects of these changes on consumer sentiment and auto expenditures can be seen by comparing Tables 6 and $9 .{ }^{28}$ There is a fair amount of im-

28. Other durables are unaffected since income has not been permitted to change. 
Table 9. Forecasts of Automobile Expenditures, Using Alternative Assumptions for Benchmark Forecast, by Half-Years 1970-72

\begin{tabular}{|c|c|c|c|c|c|}
\hline \multirow[b]{2}{*}{ Expenditure or index } & \multirow{2}{*}{$\frac{1970}{\begin{array}{c}\text { Second } \\
\text { half }\end{array}}$} & \multicolumn{2}{|c|}{1971} & \multicolumn{2}{|c|}{1972} \\
\hline & & $\begin{array}{l}\text { First } \\
\text { half }\end{array}$ & $\begin{array}{l}\text { Second } \\
\text { half }\end{array}$ & $\begin{array}{l}\text { First } \\
\text { half }\end{array}$ & $\begin{array}{l}\text { Second } \\
\text { half }\end{array}$ \\
\hline \multicolumn{6}{|c|}{$\begin{array}{l}\text { Automobile expenditures (seasonally } \\
\text { adjusted annual rate in billions of } \\
1958 \text { dollars) }\end{array}$} \\
\hline Equation (11) & $\$ 35.2$ & $\$ 33.3$ & $\$ 33.5$ & $\$ 35.2$ & $\$ 35.9$ \\
\hline Equation (12) & 35.7 & 34.6 & 34.8 & 36.0 & 36.2 \\
\hline Equation (13) & 35.5 & 33.5 & 34.3 & 35.9 & 36.2 \\
\hline $\begin{array}{l}\text { Index of consumer sentiment } \\
\quad(\text { first quarter } 1966=100)\end{array}$ & 79.3 & 85.8 & 91.2 & 93.7 & 93.3 \\
\hline
\end{tabular}

Source: Derived by author using data in Table 8.

provement in consumer sentiment, which now regains its early 1969 level in 1972.

The auto market is slightly improved, especially as viewed by equation (13), but the increases are distinctly small. This and other similar experiments clearly lead to the conclusion that the price and sentiment variables can vary within broad but likely ranges and still produce only "marginal" changes in consumer spending. It should be noted, however, that these changes-while small in actual magnitude-may not be all that small in comparison with the forecasting errors typically made (and subject to magnification through large multiplier effects) by quarterly forecasting models.

Variation of the income assumptions embodied in the benchmark forecast-again within a likely range-produces heavier impacts on durable expenditures. Table 10 contains the income and employment data corresponding to a somewhat stronger economic forecast for the period after 1970. Such a stronger growth of total demand would have to originate outside the auto sector. The price assumptions are the same as those in the benchmark forecast, not because that is reasonable, but in order better to isolate the income-employment effects on expenditure. It is clear that by the second half of 1971, the stronger growth assumptions have produced a markedly higher level of spending on consumer durables (compare Tables 6 and 11). Further, comparison of Tables 6, 9, and 11 reveals that the effects of the income-employment changes (as specified) on consumer sentiment are much weaker than the price effects previously specified. 
Table 10. Forecasts of Selected Economic Measures Assuming Growth Higher than the Benchmark Forecast, by Half-Years 1970-72

\begin{tabular}{|c|c|c|c|c|}
\hline \multirow[b]{3}{*}{$\begin{array}{l}\text { Year } \\
\text { and } \\
\text { half }\end{array}$} & \multicolumn{3}{|c|}{ Annual rate of growth ${ }^{\mathrm{a}}$} & \multirow{3}{*}{$\begin{array}{c}\text { Unemployment } \\
\text { rate for males } \\
20 \text { years } \\
\text { and over }\end{array}$} \\
\hline & \multirow[b]{2}{*}{$G N P$} & \multicolumn{2}{|c|}{ Disposable personal income } & \\
\hline & & Total & $\begin{array}{c}\text { Net of } \\
\text { transfer } \\
\text { payments }\end{array}$ & \\
\hline 19702 & $2.0 \%$ & $1.5 \%$ & $1.0 \%$ & $3.80 \%$ \\
\hline $\begin{array}{r}19711 \\
2\end{array}$ & $\begin{array}{l}4.0 \\
6.0\end{array}$ & $\begin{array}{l}3.0 \\
5.0\end{array}$ & $\begin{array}{l}3.0 \\
5.5\end{array}$ & $\begin{array}{l}4.05 \\
3.80\end{array}$ \\
\hline $\begin{array}{r}19721 \\
2\end{array}$ & $\begin{array}{l}6.0 \\
6.0\end{array}$ & $\begin{array}{l}6.0 \\
6.0\end{array}$ & $\begin{array}{l}6.0 \\
6.0\end{array}$ & $\begin{array}{l}3.10 \\
2.50\end{array}$ \\
\hline
\end{tabular}

Source: Author's estimates (see Table 5).

a. Based on data in billions of 1958 dollars.

Nearly all of the greater strength of the auto performance in Table 11 is therefore due to the more rapid growth in income embodied in the higher growth forecast. In the event that such growth should materialize, it would help to alleviate the stock effect and 1972 would likely witness a rebound in

Table 11. Forecasts of Expenditures for Automobiles and Other Durables, Assuming Growth Rate Higher than Benchmark Forecast, by Half-Years 1970-72

\begin{tabular}{|c|c|c|c|c|c|}
\hline \multirow[b]{2}{*}{ Expenditure or index } & \multirow{2}{*}{$\begin{array}{c}1970 \\
\begin{array}{c}\text { Second } \\
\text { half }\end{array}\end{array}$} & \multicolumn{2}{|c|}{1971} & \multicolumn{2}{|c|}{1972} \\
\hline & & $\begin{array}{c}\text { First } \\
\text { half }\end{array}$ & $\begin{array}{l}\text { Second } \\
\text { half }\end{array}$ & $\begin{array}{c}\text { First } \\
\text { half }\end{array}$ & $\begin{array}{l}\text { Second } \\
\text { half }\end{array}$ \\
\hline $\begin{array}{l}\text { Expenditures (seasonally adjus } \\
\text { annual rate in billions of } 19 \\
\text { dollars) }\end{array}$ & & & & & \\
\hline $\begin{array}{l}\text { Automobiles } \\
\text { Equation (11) } \\
\text { Equation (12) } \\
\text { Equation (13) }\end{array}$ & $\begin{array}{r}\$ 35.1 \\
35.6 \\
35.4\end{array}$ & $\begin{array}{r}\$ 33.2 \\
34.5 \\
33.3\end{array}$ & $\begin{array}{r}\$ 33.8 \\
34.9 \\
34.3\end{array}$ & $\begin{array}{r}\$ 36.0 \\
36.6 \\
36.3\end{array}$ & $\begin{array}{r}\$ 37.8 \\
38.2 \\
38.0\end{array}$ \\
\hline $\begin{array}{l}\text { Other durables } \\
\text { Equation (15) }\end{array}$ & 46.7 & 49.0 & 51.0 & 52.5 & 55.5 \\
\hline $\begin{array}{l}\text { Index of consumer sentiment } \\
\quad(\text { first quarter } 1966=100)\end{array}$ & 79.1 & 84.8 & 88.2 & 90.1 & 91.8 \\
\hline
\end{tabular}

Source: Derived by author using data in Table 10. 
the auto market, carrying expenditure levels well beyond those of 1969 to a new peak above that of any quarter in the 1960s. It is unlikely that any worsening of price performance (relative to the benchmark forecast), which might in fact accompany a higher growth scenario, would have an appreciable impact on the corresponding expenditure forecasts.

\section{Conclusions}

Economists who make substantial use of sentiment variables, stock market changes, and other such non-real (as distinct from unreal) quantities in their own forecasts of consumer spending tend to shun the structural stock-adjustment framework preferred by the majority of econometric forecasters. The latter, in turn, have tended to reject the complex of stock market-sentiment-expectational variables as of dubious value and in any case unpredictable. There no longer appear to be many good reasons to maintain this dichotomy of approaches.

Changes in consumer sentiment-if properly filtered-do improve the forecasting accuracy of a stock-adjustment model of automobile expenditures. It is apparently possible to forecast ahead at least one quarter (and perhaps further investigation will suggest still longer) on the basis of the current quarter's sentiment index. It is also possible to forecast the systematic component of the sentiment index one quarter ahead with the aid of current stock market prices, thus permitting an auto forecast at least two quarters ahead without a forecast of stock market prices. Beyond this, the need to forecast the stock market may well establish the practical limit of the usefulness of the sentiment index in auto forecasting, except for conditional projections of the kind undertaken in the previous section. Nonetheless, the potential of meaningful improvement in forecasting accuracy for two quarters into the future is not to be taken lightly. Many four-quarter forecasts would have been much more accurate if only the errors present in the first quarter or two of the forecast could have been measurably reduced. 


\section{AP P ENDIX}

\section{Calculation of Stocks and Elasticities}

\section{Auto Stock}

The actual stock of automobiles (in 1958 dollars) was calculated under the assumption of a constant rate of depreciation, $100 v$ percent per quarter. Under this assumption, if $C A R K_{-i}$ represents gross purchases of autos $i$ quarters ago, then $(1-v)^{i} C A R K_{-i}$ represents the currently surviving (undepreciated) portion of that purchase. The current stock of autos can therefore be obtained by adding up the currently surviving portions of all previous auto purchases, hence

$$
\text { (A.1) } K A=\sum_{i=0}^{\infty}(1-v)^{2} C A R K_{-i}
$$

and what remains is to determine $v$.

If it is further assumed that beyond a certain age, say $x$ quarters, a car is no longer considered part of the available stock, but merely something to be disposed of for its scrap value, then the above expression becomes

$$
K A=\sum_{i=0}^{x}(1-v)^{i} C A R K_{-i}
$$

If the scrap value is denoted by $s$, then $(1-v)^{x}=s$. Choosing reasonable values such as forty quarters (ten years) for $x$ and 0.04 for $s,{ }^{1}$

$$
(1-v)^{40}=0.04
$$

Equation (A.3) can be solved to yield $v=0.078$, a quarterly depreciation rate quite consistent with the rule-of-thumb that a car loses 25 percent of its value after one year. ${ }^{2}$ The stock data used in the auto equations in this paper were thus obtained by applying the formula

$$
K A=\sum_{i=0}^{40}(1-0.078)^{i} C A R K_{-i} .
$$

1. This seems reasonable since it implies that a car costing $\$ 2,500$ new would be "scrapped" for $\$ 100$ after ten years.

2. Chow has come up with a similar figure in his studies, and Evans uses the same technique to derive his stock series. See Chow, "Statistical Demand Functions for Automobiles"; and Evans, Macroeconomic Activity. 


\section{Long-term Elasticities in the Auto Equation}

In order to calculate the long-run elasticity of $C A R K$ with respect to $X$, a typical explanatory variable, the analysis begins with a dynamic equation of the form ${ }^{3}$

$$
C A R K=a X+b K A_{-1} .
$$

The difficulty inherent in the calculation is seen by noting that ${ }^{4}$

$$
K A_{-1}=C A R K_{-1}+(1-v) K A_{-2},
$$

so that

$$
C A R K=a X+b C A R K_{-1}+b(1-v) K A_{-2},
$$

and a change in $X$ therefore leads to a sequence of changes in $C A R K$ over time. Calculation of the ultimate (long-run) change in $C A R K$ thus requires determination of the steady-state version of equation (A.5). To this end, equation (A.5) is lagged one period and multiplied by $(1-v)$ to obtain

$$
\text { (A.8) } \quad(1-v) C A R K_{-1}=(1-v) a X_{-1}+(1-v) b K A_{-2} \text {. }
$$

Subtracting (A.8) from (A.5) yields

(A.9) $C A R K=a X-(1-v) a X_{-1}+b\left[K A_{-1}-(1-v) K A_{-2}\right]$

$$
+(1-v) C A R K_{-1} \text {. }
$$

By equation (A.6), $\left[K A_{-1}-(1-v) K A_{-2}\right]=C A R K_{-1}$, so that

$$
\text { (A.10) } \quad C A R K=a X-(1-v) a X_{-1}+(1-v+b) C A R K_{-1} \text {. }
$$

In the long run, when $X$ and $C A R K$ have reached their equilibrium (steadystate) values, time lags can be neglected, so that (A.10) becomes

$$
C A R K=a X-(1-v) a X+(1-v+b) C A R K,
$$

or

$$
\text { (A.11) } \quad C A R K=\frac{a v}{v-b} X .
$$

3. $C A R K$ and $K A_{-1}$ are defined in the body of the paper, while $X$ stands for any other variable, such as income or price.

4. This would be precisely correct if the stock had been calculated using an infinite series as in equation (A.1). It is very nearly correct in the case of (A.4). 
Thus, in the long run, the partial derivative is

$$
\frac{\partial C A R K}{\partial X}=\frac{a v}{v-b}
$$

and the long-run elasticity of $C A R K$ with respect to $X$ is approximated by multiplying the expression in (A.12) by the ratio of the mean of $X$ to the mean of $C A R K$.

\section{Calculation of the Stock of Other Durables}

For reasons mentioned in the body of the paper, it seemed inappropriate to assume a constant rate of depreciation in the case of other durables. Instead, use was made of the series, "Capital consumption on consumer durables," published in the flow of funds section of the Federal Reserve Bulletin. ${ }^{5}$ By constructing a series on capital consumption of autos ${ }^{6}$ and subtracting this from the Federal Reserve series for capital consumption of all consumer durables, a series on "capital consumption of other durables" was obtained. Subtraction of this series (after deflating by the other durables deflator) from gross real expenditures on other durables left a series on net real expenditures NETODCK. Finally, the assumption that the depreciation rates could be considered equal in two successive quarters yielded the following three equations in three unknowns $\left(K O_{0}, K O_{1}, v\right)$

$$
\begin{aligned}
O D C C A_{i} & =v K O_{i-1}, i=1,2 \\
K O_{1} & =K O_{0}+N E T O D C K_{1},
\end{aligned}
$$

where $O D C C A_{i}$ is the deflated value of capital consumption for other durables in quarter $i$ and $K O$ is capital stock. Choosing time zero as 1953:4 and solving equation system (A.13) yielded a depreciation rate of 0.1202 and an initial capital stock

$$
K O_{1953: 4}=137.10 \text { (billions of } 1958 \text { dollars). }
$$

The capital stock series was then calculated by successive application of equation (A.14) starting with 1954:1.

$$
K O=K O_{-1}+N E T O D C K .
$$

5. Federal Reserve Bulletin, Flow of Funds, Table 4, line 12. This series assumes constant depreciation rates for each of ten component parts of the durables total and permits changes in component weights over time.

6. Obtained by calculating $(A U T O D)(0.078) K A_{-1}$. 
The result did not yield a series that displayed a constant depreciation rate. ${ }^{7}$ Rather, the stock series implied a continuous decline in $v$ from about 0.12 in 1954 to about 0.09 in 1967, after which $v$ began to rise, reaching about 0.10 in 1969. The average value of $v$ over the 1954-68 sample period was 0.098 . Several alternative stock series constructed with constant aggregate depreciation rates were tried in the other durables equation. The variable rate series was clearly preferable in terms of all the usual criteria of fit, expected sign, pattern of residuals, and so on.

The long-run income elasticity corresponding to the other durables equation was calculated exactly as in the case of the auto equation with "the" value of $v$ taken at its sample mean of 0.098 .

7. Applying the formula $K O=O D C K+(1-v) K O_{-1}$ to the resulting stock series and solving for $v$ each quarter did not imply a constant value for $v$. 


\section{Comments and Discussion}

Gardner Ackley: I have always felt that consumers' attitudes and psychology somehow must be important in consumer spending, that they must have some role in fluctuations of sales of durables and in fluctuations of the savings rate. I am, of course, glad to have this view confirmed. I still find a few puzzles in the explanation. As the paper shows, and as we have known for a long time, the consumer sentiment index does improve the explanation of either total consumer expenditures or consumer durables expenditures when it is used in a simple model along with income.

The first finding of this paper, however, is that consideration of consumer sentiment does not aid the explanation in a "more sophisticated model" including the automobile stock, relative prices, and the unemployment rate. I am unable to understand why the stock-adjustment process and relative price elasticity somehow took the place of the index of consumer sentiment in explaining consumer expenditures. Obviously, stock adjustment and relative prices belong in a better explanation of consumption, but they neither are explained by, nor clearly do they explain, consumer sentiment. Rather, they are quite independent of it.

The only conclusion I can reach is that somehow the role of sentiment in the simpler model was entirely spurious, since it was replaced by factors that apparently had nothing to do with sentiment. My first suspicion was that the unemployment rate was somehow picking up the role of the sentiment variable in the more sophisticated model. For a given total of real disposable income, a higher rate of unemployment may imply a different distribution of income; but that distribution of income is not obviously more conducive to selling automobiles.

It seems to me that the role of unemployment in this equation has to be related somehow to psychological considerations-people who still are 
working feel increasingly insecure because of the rise in the unemployment of others. Perhaps the principal justification for including an unemployment variable is purely pragmatic: Everybody does it in an automobile equation and it works. I am still not entirely satisfied. I would like to ask whether the unemployment rate was tried as one of the explanatory variables of the consumer sentiment index, and whether it should not be considered.

It seems somewhat surprising - after being told that the index of consumer sentiment is reasonably satisfactorily explained by real variables, and that it adds significantly to the explanation of consumption in a simple, naive model-to learn that only substantial variations in the consumer sentiment index matter, whereas the other movements are meaningless for forecasting. I would feel happier if it were shown either that the real variables that are used to explain the consumer sentiment index do a better job explaining the filtered index than they do the unfiltered index and/or that the filtered index works better in the simple model than does the unfiltered index.

Finally, I continue to be puzzled by the projections at the end of the paper. For something as cyclically volatile as auto sales, the behavior of these predicted auto sales seems to be terribly stodgy. In the low benchmark forecast, real disposable income is up roughly 9 percent between the second half of 1969 and the second half of 1972, but auto sales on any of the equations are at best just back to the 1969 level. Even in the higher growth forecast, in which the unemployment rate gets back to its level in the second half of 1969, the best one can say is that it will be the highest quarter auto sales ever had, and that is not good enough for me.

F. Thomas Juster: My interpretation of the filtered index and my reasons for constructing it this way have an analytical as well as an empirical foundation. I'd like to discuss that foundation, which was not fully revealed by Saul Hymans' description. My view is that the sentiment index really stands for uncertainty. When uncertainty is not changing, the other variables in an auto demand equation are perfectly capable of explaining automobile sales. But when uncertainty is either narrowing or broadening, that fact is never fully discounted or foreseen; it will cause deviations from the levels of demand implied by a normal set of variables. It follows that, if the sentiment variable measures uncertainty, its inclusion is in principle undesirable when it is not going anywhere, that is, wandering at random. 
Its inclusion is essential when it is going either up or down significantly because that is precisely when the other variables will not capture the change in uncertainty that is taking place and the impact of that change on automobile sales.

That is basically the analytical structure of the filtered variable. The decision rules are quite arbitrary. Anybody can fiddle with them and find a better set, but it won't make very much difference empirically. The filtered variable is designed to provide an empirical measure of the notion that changing uncertainty is significant in equations with variables that explain behavior in the absence of changing uncertainty; but that it is unnecessary and even detrimental to those same equations when no appreciable change is going on. I found, incidentally, it works very well in a somewhat simpler model of automobile demand than Hymans'.

Second, I'd like to offer an explanation for the finding that the sentiment variable does not help explain expenditures on household durables. My explanation is simply that these expenditures are not discretionary. We tend to think of purchases of durables as discretionary because they seem postponable. But a washing machine costs $\$ 225$ or $\$ 250$ - only a third of a month's salary for a great many Americans-and it is like the car insurance bill in magnitude. It is not a big-ticket item, and in that sense should not be viewed as in a discretionary category. Consequently, variables like consumer sentiment will not play much role.

They do, however, play a role for automobiles, as Hymans shows. There are other categories of discretionary expenditures. Perhaps the most important would be certain services that have large unit costs and are luxuries, and therefore should be classified as discretionary-expensive vacations, for example.

Third, I am just as puzzled as Gardner Ackley by the bearish projections of automobile demand for 1971 and 1972. Most of the variables in Hymans' model would be stimulating automobile demand. The only variable with a negative effect is the growing stock of cars. I am surprised that the stock appears to have such an enormous depressing effect.

I have a few comments on the structure of the basic stock-adjustment model used by Hymans. Of greatest importance is the nature of the dependent variable - the thing we are trying to explain. Hymans should be commended for taking expenditures on mobile homes out of the, national accounts series on automobile outlays. But he leaves in expenditures on automobile parts, and they muddy the equation, even though they can't do 
much damage. Sales of automobile parts have a negative association with sales of new automobiles, as one would expect, if you try to explain the two separately.

Moreover, the automobile purchases that we are trying to explain are those made by consumers. The data from the national accounts, however, are based on a trend estimate that 15 percent of new car purchases are made by business and 85 percent by households. There is an alternative source for an estimate of household purchases-the Census survey of consumers' buying expectations which collects that information directly. The survey implies that the 85-15 breakup was, until two years ago, a good measure of trend, but a poor measure of quarterly variations-which are often different in direction for the survey and the " 85 percent" assumption.

For the last two years, the 15 percent figure begins to look bad, even as a trend estimate. The ratio has, in fact, been rising systematically. The average for the last two years is more like 17 percent business sales and 83 percent household sales. This may be particularly important in the very large error of all automobile equations in the fourth quarter of 1969. Taking what the Census survey says consumers bought, rather than what the national accounts say they bought, we do not get that large error. For that quarter, there is a 5 or 6 percent difference in the sales level between the two estimates. In short, the trouble one has explaining "consumer behavior" is compounded when the data themselves are not a clear reflection of consumer behavior.

Finally, total auto expenditures in constant prices are a product of two parts - the total number of units sold and the average real price per unit, that is, actual dollars paid per unit deflated by a price index. These are the quantity and quality dimensions: consumers' preferences about how many cars they want and how much value they want when they do buy a car. When these are looked at separately, we find that real value per unit is explained well by lagged real income, and that nothing else helps much. The variables that explain the number of units sold are a very different set. The level of real income doesn't work. Income changes, unemployment rates, and the psychologically sensitive factors like the consumer sentiment index and expectations explain unit sales.

One could seek to explain automobile expenditures by multiplying the equation for unit sales by the one for real price per car. When the two equations are multiplied together the resulting equation is statistically messy and inelegant, with all sorts of cross-product terms. In some experi- 
ments I have made, the results support the multiplicative specification, but I am not prepared to recommend reliance on such an equation.

One other comment on the joint use of expectational and anticipatory variables with regular objective variables: Improved results could, I think, come from a model that uses two expectational variables-one on purchase plans and one on sentiment-in addition to objective factors. Experiments on such a model can be performed only since 1960, when the Census launched the quarterly survey that gave us the first regular and reliable measure of purchase plans. Some results obtained for the period 1960-67 are in a paper that will soon be available. ${ }^{1}$ They suggest that purchase expectations reflect essentially all the adjustment of demand to changes in income, the filtered sentiment variable reflects changes in uncertainty, and unemployment rates reflect events that are unforeseen in purchase plans and not captured by the filtered sentiment variable. The results with just these three variables for automobiles are an improvement over those that I have been able to obtain with any set of objective variables, including ones with a variety of distributed lags. It is also interesting that the relative price variable seems to remain relevant-it is not replaced by the survey variables. One interpretation that I am quite prepared to accept is that prospective buyers typically enter the auto market with only a vague notion of price, and the actual price they find is apt to be a surprise.

Saul Hymans: Gardner Ackley asked whether the unemployment rate would be important in the equation explaining consumer sentiment. The answer is, "No." It does not help when the other variables are included. I gave it all kinds of chances.

He raised another interesting question: Why is the unfiltered index of consumer sentiment so good in an income-type equation and so bad in a stock-adjustment equation? If you look at the way the consumer sentiment index is constructed, it is clear that it contains not only the aspects of uncertainty or changing uncertainty that Juster emphasized, but also some aspects of the buying plans. These plans get into the sentiment index directly and also indirectly because buying plans color one's response to some other questions, such as: Do you think the next six months is a good time to buy major household durables? A good time to buy a car?

In the case of a "naive" income-type equation, the income variable by

1. F. Thomas Juster, "Consumer Anticipations and Models of Durable Goods Demand," Economic Forecasts and Expectations (National Bureau of Economic Research, 1969). 
itself is a sufficiently poor determinant of automobile spending, particularly of quarter-to-quarter movements, that the component of the sentiment variable that reflects buying plans helps a great deal. On the other hand, in a stock-adjustment equation, relative prices and the lagged stock are included. I think the buying plans component of the sentiment index is swamped by the better determinants of buying plans included in the stockadjustment mechanism. Thus we get a very weak performance from the sentiment index in the stock-adjustment version until we filter the index and focus on the uncertainty aspects of it.

\section{General Discussion}

One strand of the general discussion focused on the practical application to forecasting of the findings about the filtered sentiment index. It was generally agreed that the usefulness was limited to a fairly short horizon of prediction. Yet it is possible, in principle, to forecast the sentiment index and use that prediction in the auto forecast. David Fand suggested, however, that the sentiment index might be a particularly difficult variable to predict. Saul Hymans said that last quarter's value of the sentiment index is sufficient for a forecast of next quarter's automobile consumption; furthermore, this quarter's variables permit a satisfactory forecast of next quarter's sentiment index, and thus make it possible to forecast auto demand two quarters ahead. That may be the practical limit to the usefulness of the sentiment index. A two-quarter forecast of the sentiment index would require a one-quarter prediction of stock market prices, among other things.

Several discussants commented on the role of relative prices in Hymans' model. Alan Greenspan pointed to the long history of a downward trend in auto prices, relative to other prices. Since relative prices were the only variable moving down over time, they might be acting as proxies for some other long-term forces with a negative impact on automobile spending. Lawrence Klein said that the price elasticities looked rather small, in comparison with his own estimates and in light of other evidence. He interpreted the move toward imported cars as offering some gross evidence of sensitivity to price. Moreover, calculations attempting to measure quality change more specifically by the "hedonic index" approach would suggest that car prices have fallen a lot more than the official price indexes show. 
R. J. Gordon noted that the Bureau of Labor Statistics seemed to be devoting increasing effort to adjustment of prices of automobiles for quality change, but does not seem to be matching that effort in the case of other commodities; this could affect the series on relative prices and the estimates of price elasticity.

Both Klein and R. J. Gordon noted the omission of any variable for credit market conditions in Hymans's automobile forecasting model. Klein thought such a variable might be particularly important for understanding demand in the 1968-70 period of high interest rates. R. J. Gordon conjectured that ignoring credit variables might bias downward the estimated income or price elasticity. Klein also noted the desirability and the difficulty of including a variable to reflect the state of the used car market.

In answer to a query, Klein reported that the Wharton model would predict a somewhat more buoyant growth in auto sales in 1971-72 than did Hymans', if the other assumptions were the same. He guessed that the difference might be a couple of billion dollars-a little more than 5 percent.

There was considerable discussion of the way that rapid income growth from 1964 to 1968 could have generated unsustainably high rates of auto sales, given the high short-term income-elasticity of demand.

To Paul Samuelson, the bearish outlook for automobile demand presented by Hymans did not necessarily seem surprising. He noted: "Any dynamic system involving stock adjustment tends to go on huge roller coaster rides. We may be in the bad part of the cycle, when it goes below the trend. With the way stocks have built up in the past, they may now be quite large, and they could have a depressing effect on sales for some years to come."

Alan Greenspan agreed with Samuelson. Like him, he did not find the results surprising. During the big buildup period, the key variables had been rising very rapidly, and they may well have generated an unsustainable growth rate. 